\title{
OPTIMAL DESIGN OF BRITTLE MATERIALS SUPERFINISHING MACHINE
}

\author{
DOBRESCU, T[iberiu] G[abriel]; PASCU, N[icoleta] - E[lisabeta]; \\ NICOLESCU, A[drian] F[lorin] \& ENCIU, G[eorge]
}

\begin{abstract}
This paper reviews theoretical and experimental research regarding brittle materials processing with superfinishing machine. The optimization of the characteristics of brittle materials superfinishing machine is very important because they directly influence the quality of workpieces surfaces. The performances of the superfinishing machine linkages are increasingly higher, due to the following requirements: very high quality workpieces surface, reduced time for feed workpieces to machine tools, better interconnections between machine tools are used in the technological process, high flexibility. Main criteria for optimal design of brittle material superfinishing machine are: energy consumption criterion, technological criterion, dynamic criterion.
\end{abstract}

Keywords: brittle material, superfinishing machines, silicon wafers, material removal rate, lapping

\section{INTRODUCTION}

The history of superfinishing machining technologies begins with primitive man, who presumably sharpened his flint knife with a piece of sandstone. Earliest records of grinding are from ancient Egypt, where many consider the grinding of metal to have begun. Modern superfinishing technology was only relatively recently established, through the introduction of grinding machines and synthetic abrasives in the nineteenth century. Developments in supefinishing technology, particularly grinding with superabrasive wheels such as diamond and cubic boron nitride wheels, are remarkable. The need for high accuracy machining and for high efficiency machining of difficult to machine materials is making the application of superfinishing technologies increasingly important.

The development trends of the superfinishing machine can be specified in this situation through the following specific requirements: more productive, more rigid and cheaper.

The development of the superfinishing machine is now also stimulated by the performances in related areas such as: the "tools" process domain (powders and abrasive pastes), the materials domain and the processing method. The quality of a superfinishing machine is appreciated as a result of: accuracy in processing and productivity. Both criteria of appreciation of a superfinishing machine depend on: the structure of the superfinishing machine linkages and rigidity of the superfinishing plates.

Main criteria for determining the characteristics superfinishing machines can be grouped into: energy consumption criterion - as higher are the properties "cutting" of abrasives materials, as lower the consumed energy for removal of material units is [1].

Technological criterion - the machinability through superfinishing of brittle materials depends on a series of technological factors: the shape and the size of the abrasive micrograins, the quality of the transport fluid, viscosity of the abrasive suspension, speed and pressure of superfinishing [1].

Material removal rate increases along with the size of the abrasive particle, increasing pressure and increasing the superfinishing speed. As higher superfinishing pressure is, as lower the roughness of the super-finished surfaces is. The superfinishing pressure is upper limited by the fragility and reduced thickness of the parts.

Dynamic criteria - the influence of the dynamic behavior of superfinishing machines on superfinishing processes with abrasive suspensions is not studied enough yet. Stiffness characteristics must be experimentally determined according to the standard dimensions of the superfinishing machine, processing precision required, roughness and productivity forecasted, given the characteristics of abrasive suspension used [1].

Given the main criteria for determining the characteristics of the superfinishing machines one may determine the main optimization criterions of superfinishing machines [2] and [3].

\section{ENERGY CONSUMPTION CRITERION}

To evaluate energy consumption in the plane parallel superfinishing is more rational to use specific mechanical work instead of the absolute values of mechanical work consumption on removing a certain material volume $\mathrm{V}$.

The specific mechanical work of superfinishing is noted with $\mathrm{L}_{\mathrm{sp}}$ and defined by the report:

$$
L_{s p}=\frac{L}{V}=\frac{F_{t} \cdot\left(v_{d} \pm v_{p}\right)}{V}\left[\frac{\mathrm{N} \cdot \mathrm{m}}{\mathrm{mm}^{3}}\right]
$$

Where: $F_{t}$ - tangential component of cutting force, $v_{d}$ - the speed of the superfinishing plate, $v_{p}$ - the speed of the workpiece which is to be processed

When one makes the experimental determination of specific mechanical work one should be considering that the tangential cutting force and volume of chipped material are not constant, varying in time. 
When calculating, it is considered the average of the superfinishing mechanical work $\left(\mathrm{L}_{\mathrm{sp}}\right)_{\mathrm{m}}$

$$
\left(L_{s p}\right)_{m}=\frac{L_{m}}{V_{m}}=\frac{\int_{t o}^{t} F_{t}(t) \cdot\left(v_{d} \pm v_{p}\right) d t}{\int_{t 0}^{t} V_{M}(t) d t}
$$

In the particular case, for a small time interval $\left(\mathrm{t}-\mathrm{t}_{0}\right)$ one may consider that the sizes remain constant $F_{t}$ and $\mathrm{V}_{\mathrm{d}}$; and $\mathrm{v}_{\mathrm{p}}$ being smaller than $\mathrm{v}_{\mathrm{d}}$ one may neglect it.

In these conditions one obtains this expression:

$$
\left(L_{s p}\right)_{m}=\frac{F_{t} \cdot\left(v_{d} \pm v_{p}\right)}{V_{M}}=\frac{F_{t} \cdot v_{d}}{V_{M}}
$$

$F_{t} \cdot v_{d}$ - is effective power of superfinishing $P_{e f}$ and (3) one can write:

$$
\left(L_{s p}\right)_{m}=\frac{P_{e f}}{V_{M}}
$$

If the effective power of superfinishing $P_{e f}$ is expressed in $[\mathrm{kW}]$, the cutting tangential force $F_{t}$ is expressed in $[\mathrm{N}]$, the speed of superfinishing plate $\mathrm{v}_{\mathrm{d}}$ is expressed in $[\mathrm{m} / \mathrm{s}]$ and the average volume of material removed $V_{M}$ is expressed in $\left[\mathrm{mm}^{3} / \mathrm{min}\right]$ then:

$$
\left(L_{s p}\right)_{m}=\frac{6120 \cdot P_{e f}}{V_{M}}\left[\frac{\mathrm{N} \cdot \mathrm{m}}{\mathrm{mm}^{3}}\right]
$$

From (5) results:

$$
P_{e f}=\frac{\left(L_{s p}\right)_{m} \cdot V_{M}}{6120}[k W]
$$

If one takes into account the specific intensity of superfinishing:

$$
V_{s p}=\frac{V_{M}}{F_{n}}
$$

Then the relation (6) becomes:

$$
\mathrm{P}_{\mathrm{ef}}=\frac{\left(\mathrm{L}_{\mathrm{sp}}\right)_{\mathrm{m}} \cdot \mathrm{V}_{\mathrm{sp}} \cdot \mathrm{F}_{\mathrm{n}}}{6120}[\mathrm{~kW}]
$$

Where one noted with $F_{n}$ - the normal component of cutting force.

The specific mechanical work of superfinishing depends on many factors including physical and mechanical properties of the material which is to be processed.

From experimental data obtained at the plane parallel superfinishing of various materials, using the same abrasive suspension (silicon carbide abrasive particles with size of $18 \mu \mathrm{m}$ and fluid transport Aquasol 1000S) showed that the mechanical work of superfinishing varies from $125\left[\mathrm{Nm} / \mathrm{mm}^{3}\right]$ in the case of the steel processing, to $6[\mathrm{Nm} / \mathrm{mm} 3]$ in the case of the germanium processing, i.e. over 20 times [1].

The Power of the superfinishing machines used today ranges from 1.5 to $10 \mathrm{~kW}$. These high values of power are justified using the intensive cutting regimes. With (6) and (8), depending on the volume of data ordering, we can calculate the effective power consumed in the superfinishing process with abrasive suspension. Considering the resulting calculations the superfinishing power required a variety of materials with different abrasive suspension not exceeding $3.5 \mathrm{~kW}, 4 \mathrm{~kW}$ power providing sufficient reserves for a possible increase in energy consumption caused by the intensive use of superfinishing machines. These results confirm that: as higher the cutting properties of the abrasive materials is, as lower the energy which to be consumed for removing of a material mass unit is.

\section{TECHNOLOGICAL CRITERION}

The areas of adjustment of plane superfinishing machines are determined by extreme limits of speed in addition by specific pressure force of superfinishing as at any cutting machine-tool.

So, the arising question is what values of cutting speed and specific pressing force of superfinishing must have a superfinishing machine to justify efficient use of abrasive suspension.

To answer this question we analyzed the influence of these technological parameters (rotation speed of the superfinishing plates and the specific pressing force of superfinishing) on the surface roughness $\left(R_{a}\right)$ and material removal rate $\left(\mathrm{Q}_{\mathrm{W}}\right)$ [1].

According to classical theory of superfinishing processes with the abrasive suspension, the increase of the speed cutting in superfinishing has a favorable influence on productivity of the process and roughness of the workpieces surface, because the following events occur: the number of abrasive particles per unit time passing through the area of superfinishing (kinematic effect) increase, which corresponds to a proportional increase of removing speed of the material processing; one decreases resistance to cutting posed by the material (speed effect), the action of this phenomenon is assessed through the increase of the limited chip section of each grain and it is a supplementary reserve of increasing speed removable rate of material (compared with kinematic effect), depending of the processed material properties and other features of superfinishing process; the percentage of abrasive particles that cuts in relation to the percentage of abrasive particles which performs a mechanical work of elasto-plastic deformation and friction mechanical work (static effect).

The machinability of brittle material on the superfinishing machine depends on a series of technological factors: the shape and size of the abrasive particle, the quality and viscosity of the fluid transport, rotation speed of the plateaus and specific pressing force of superfinishing [4], [5] and [6].

Analyzing the data from experimental research of the plane parallel superfinishing machine MELCHIORRE SP3/600/2RP, as those from reference material on superfinishing plan parallel machines, show that by increasing the cutting speed plate, rate material removal $\left(\mathrm{Q}_{\mathrm{W}}\right)$ also increases.

As higher the speed of the plates is, as faster the abrasive particles roll up on the workpieces surface, removing a larger amount of material in the same time.

The intensive study of dependence: $Q_{\mathrm{w}}=\mathrm{f}(\mathrm{v})$ (the removal rate of material depending on the superfinishing plate rotation) concluded that the material removal rate is proportional to the speed of the superfinishing plates. 




Fig. 1. The variation of material removal rate

When processing the silicon wafer by lapping on plane parallel superfinishing machine MELCHIORRE SP3/600/2RP, the increase of rotation speed of the superfinishing plates from $10 \mathrm{rev} / \mathrm{min}$ to $30 \mathrm{rev} / \mathrm{min}$ resulted in increased material removal rate of $2 \ldots 3$ times by depending on the specific pressure force (fig. 1).

Most lapping operations today employ liquids as coolants. These are beneficial to the abrasive process for reducing friction in the plate - workpiece contact zone (lubricating effect), removing the lapping swarf (flushing effect), and for carrying away some of the thermal energy dissipated in the contact zone (cooling effect)

Experimental research of the dependence of material removal rate depending on the rotation speed of the superfinishing plate which was done in the following conditions: two sizes of abrasive particles made from silicon carbide have been used (\# 600 and \# 320); transport fluid was Aquasol 1000S; the concentration of abrasive suspension was: 2700 grams of abrasive particles to 5 liters of transport fluid; silicon wafers with a diameter of $76.5 \mathrm{~mm}$ (3 inches) have been processed; specific pressure force was: $4144 \mathrm{~N} / \mathrm{cm}^{2}, 3315 \mathrm{~N} / \mathrm{cm}^{2}$, $2486 \mathrm{~N} / \mathrm{cm}^{2}, 1657 \mathrm{~N} / \mathrm{cm}^{2}, 0.828 \mathrm{~N} / \mathrm{cm}^{2}$.

According to the graph in Fig. 1 material removal rate increases with the increase of the abrasive particle size, the increase of specific pressure force and the increase of rotation speed lapping plate.

In Fig. 1 is shown the variation of material removal rate depending on the plate rotation speed, abrasive particles size and specific pressure force, if the lapping process of silicon wafer with a diameter of $76.5 \mathrm{~mm}$ superfinishing machine MELCHIORRE SP3/600/2RP.

After the experimental researches, it was noted that the surface roughness of silicon wafers is independent of the rotation speed of superfinishing plates (the roughness varied insignificantly $3 \ldots .5 \mathrm{~nm}$ ).

The independence of workpiece surface roughness towards the rotation speed of the superfinishing plates it was inevitable, because the depth of abrasive particles penetration in the workpiece does not change one with the modification of rotation speed of superfinishing plates.

However, superfinishing plates rotation speed is upper limited by the need to maintain a uniform abrasive suspension film which is uniform distributed between the superfinishing plate and workpieces (with the rotation speed increase of superfinishing plates, the centrifugal force acting on the abrasive particles also increase, which will lead to "breaking" abrasive suspension film between superfinishing plate and workpieces).

Another factor which limits the increase rotation speed of superfinishing plates is the induced temperature in the workpiece [1].

The intensive study of dependence of the material removal rate depending on specific pressure force concluded that increase the specific pressure force leads to the increase material removal rate [7].

In the experimental research of superfinishing of silicon wafer it was noted that specific pressure force should not exceed $5 \mathrm{~N} / \mathrm{cm}^{2}$.

Using higher specific pressure force leads the compromise of surface quality.

Maximum specific pressure force is determined by the maximum allowable depth of penetration of cracks in the mass of workpiece, which are generated by the penetration of sharp vertex or sharp edges of abrasive micrograins.

Specific pressure force in the processing of silicon wafers is upper limited by the fragility and their reduced thickness.

In order not to compromise the quality of the workpiece surface, maximum allowable depth of cracks in the body of piece must be equal with the surface roughness $\mathrm{R}_{\mathrm{z}}$ of the workpiece.

Given the dependence of superfinishing workpieces surface roughness through superfinishing by the rotation speed of the plates superfinishing and by the specific pressure force, from experimental research showed that the superfinishing plan machine motor drive must provide a rotation speed range of plates between $15 \ldots 40$ $\mathrm{rot} / \mathrm{min}$.

If the technological parameters of superfinishing process are chosen properly it is possible to avoid the processing of silicon wafers in two stages (a roughing lapping followed by a finishing lapping).

\section{DYNAMIC CRITERION}

Although in the reference material there are some general recommendations regarding the conditions to be accomplished by the superfinishing machines, these cannot be considered satisfactory for those who want to use these machines with maximum efficiency.

The influence of dynamic behavior of superfinishing machines on superfinishing process of abrasive material with abrasive emulsions is not studied enough. 
Some qualitative aspects are presented in [2], [8] and [9] which show that by increasing the vibration amplitude, it also increases: the height of workpieces surface micro-roughness and the specific pressure pulsation of superfinishing. The elastic systems of superfinishing machines are considered as possessing a single degree of freedom.

The system simplification is justified by the deformations of the workpiece; bed and pillar are very small compared with those of the whole upper plate and lower plate.

To establish a relationship between the dynamic characteristics of superfinishing machine and characteristics of the process of superfinishing with abrasive suspension one may use the dynamic cutting stiffness coefficient $\mathrm{K}$ [1]:

$$
K=K_{0}\left[1+\frac{2}{3} \beta \cdot\left(\frac{\alpha}{\gamma}-\frac{\eta \cdot\left(c+K_{0}\right)}{\gamma \cdot K_{0} \cdot c \cdot t_{l}}\right)\right]
$$

Where: $\mathrm{K}_{0}$ is the cutting dynamic stiffness when autovibration of superfinishing are missing; $\mathrm{c}$ and $\eta$ represent the stiffness and the damping coefficient of superfinishing plate; $\alpha, \beta, \gamma$ - are the dependence of polynomial coefficients between the normal cutting force $\mathrm{F}_{\mathrm{z}}$, and $\mathrm{z}$ - system break down:

$$
F_{z}(z, \dot{z})=K_{0} \cdot\left(t_{l}-z\right) \cdot\left(1+\alpha \cdot \dot{z}+\beta \cdot \dot{z}^{2}+\gamma \cdot \dot{z}^{3}\right)
$$

Where: $t_{1}$ - is the setted cutting depth.

Break down system - $\mathrm{z}$ is determined by this relation:

$$
z=t_{l}-t_{e f}=\frac{K_{0} \cdot t_{l} \cdot\left(1+0.5 \cdot \beta \cdot A^{2} \cdot \omega^{2}\right)}{c+K_{0} \cdot\left(1+0.5 \cdot \beta \cdot A^{2} \cdot \omega^{2}\right)}
$$

Where: $T_{E F}$ - is the effective superfinishing depth, $\omega$ and $\mathrm{A}$ represent frequency, especially the autovibration amplitude in plane superfinishing.

Depending on the stiffness coefficient $\mathrm{K}$, superfinishing effective depth is given by:

$$
t_{e f}=t_{l} \frac{c}{c+K}
$$

Given the equation (12), one may calculate the volume of cutting material with the formula:

$$
V_{M}=t_{e f} \cdot A_{p} \cdot n_{p}=t_{l} \cdot \frac{c}{c+K} \cdot A_{p} \cdot n_{p}
$$

Where $A_{p}$ - represent the workpiece area which processes and $\mathrm{n}_{\mathrm{p}}$ - number of pieces that are simultaneously processed.

Given the relationship (9), the expression becomes:

$$
V_{M}=\frac{t_{l} \cdot A_{p} \cdot n_{p}}{1+\frac{K_{0}}{c}+\frac{2}{3} \cdot K_{0} \cdot \beta \cdot \frac{\alpha}{\gamma \cdot c}-\frac{\frac{2}{3} \cdot K_{0} \cdot \beta \cdot \eta \cdot\left(c+K_{0}\right)}{\gamma \cdot K_{0} \cdot c^{2} t_{l}}}
$$

According to equation (14) it is shown that superfinishing process productivity increases if the superfinishing plates stiffness also increases.

As the average normal cutting force $F_{t}$, this may be expressed as:

$$
\bar{F}_{z}=K \cdot t_{e f}=K \cdot \frac{c}{c+K} \cdot t_{l}
$$

According to (15) the increase of superfinishing plate stiffness leads to the increase of superfinishing normal cutting force $F_{t}$.
The stiffness characteristics must be experimentally determined depending on the machine tools dimensions, the required processing precision, the roughness and the expected productivity given the abrasive material characteristics and the workpiece material.

\section{CONCLUSION}

After the theoretical and experimental research regarding brittle materials processing with superfinishing machines and considering the three criteria (energy, technology and dynamic criterion) one may determine: the optimum value of engine power of drive of superfinishing plates, the rotation speed of the superfinishing plates, the specific pressure force and superfinishing machines stiffness.

Superfinishing machining has the characteristic that help identify suitable applications, namely small chip size and self-sharpening of the tool. These characteristics give the process a stability of sharpness and a level of surface finish that is difficult to attain by any other process. It is also applicable for machining hard and brittle materials which currently cannot be machined by any other process.

Environmental considerations and their legal and economic implications will play a major role in the development of new superfinishing technologies, particularly in fluid minimization or elimination strategies

\section{REFERENCES}

[1] Dobrescu, T. (1998). Cercetări prind optimizarea maşinilor de superfinisat material fragile, Ph.D. Dissertation, Machine and Manufacturing Systems Department, University Politehnica of Bucharest, Romania

[2] Bifano, T. G.; Dow, T, A. \& Scattergood, R. O. (1991). DuctileRegime Grinding: A New Technology for Machining Brittle Materials, Journal of Engineering for Industry, No. 113, 1991, pp. 184-189

[3] Inasaki, I.; Tönshoff, H. \& Howes, T. D. (1993). Abrasive machining in the future, Annals of the CIRP, No. 42, 1993, pp. 723-731

[4] Dobrescu, T.; \& Anghel, F. (2008). Surface grinding method of silicon wafers, Annals of DAAAM for 2008\& Proceedings of 19th, 22-25 october 2008, Trnava, ISSN1726-9679, ISBN 978-3901509-68-1, Katalinic, B. (Ed.), pp. 0395-0396, Publisher by DAAAM International, Slovakia

[5] Inasaki, I. (1987). Grinding of Hard and Brittle Materials, Annals of the CIRP, No. 36, 1987, pp 1-9

[6] Dobrescu, T.; Enciu, G. \& Nicolescu, A. (2009). Selection of process parameters in grinding ceramics, Annals of DAAAM for 2009\& Proceedings of 20th, 25-28 november 2009, Vienna, ISSN1726-9679, ISBN 978-3-901509-70-4, Katalinic, B. (Ed.), pp. 0361-0362, Publisher by DAAAM International, Austria

[7] Chen, X.; Rowe, B.; Mills, B. \& Allwnson, D. (1998). Analysis, and Simulation of the Grinding Process, In: International Journal of Machine Tools \& Manufacture, Vol. 38, No. 1-2, pp. 41 - 49

[8] Dobrescu, T.; Opran, C.; Jiga, G. \& Georgescu, L. (2011). Polishing of silicon wafers, Annals of DAAAM for 2011 \& Proceedings of 22nd, 23-26 november 2011, Vienna, ISSN17269679, ISBN 978-3-901509-83-4, Katalinic, B. (Ed.), pp. 04390440, Publisher by DAAAM International, Austria

[9] Trumpold, H.; Hattori, M.; Tsutsumi, C. \& Melzer, C. (1994). Grinding Mode Identification by Means of Surface Characterization, Annals of CIRP, No. 43, pp. $479-481$ 